\title{
A Preliminary Study on Popularizing Indian Handicrafts Using Internet Technology - A Bengal Specific Study
}

\author{
Arunava Dalal $^{1 *}$, Dr. Subrata Chattopadhyay ${ }^{2}$ \\ ${ }^{1}$ Research Scholar, University of Engineering \& Management, Kolkata \\ ${ }^{2}$ Professor, University of Engineering \& Management, Kolkata, \\ *Corresponding author.Email: arunava.dalal@gmail.com
}

\begin{abstract}
The handicraft sector is unorganized and it is the second-largest employment generating sector in India after agriculture. The majority of the artisans belong to the socially and economically backward section of the society. So working towards identifying the issues being faced by this sector and addressing them will improve the socioeconomic condition of the craftspeople. The present study has tried to list the major issues plaguing the Indian handicraft sector and the artisans. Qualitative content analysis has been adopted to capture the empirical observations and to decipher the different variables impacting the artisans and the sector. The data for the analysis was collected through in-depth interviews of forty-five artisans from different parts of Bengal. Based on the findings, the paper has conceptualized a model, with internet technology being the enabler, addressing the identified constraints to improve the socio-economic condition of the artisans so that they move towards having a sustainable livelihood
\end{abstract}

Keywords: E-commerce, Bottom of the pyramid, Online market place, Sustainable marketing, Handicrafts

\section{INTRODUCTION}

For ages, one of the modes for human beings to express their creativity has been through arts and crafts. The forms of representations have changed over the years, but the creativity and artistry have survived the test of time to enthrall us, and major sources of their depictions have been through handicrafts. These pieces of work are prepared in a traditional way where the processes of preparation of these crafts, which bear the signature of a place or a specific group of people, have been handed over to the present generation by their ancestors.

A few more characteristic of handicrafts is that, as they are not machine produced, "mass production" is not a concept associated with them. Also, in India, the people who are involved in this trade majorly belong to scheduled tribes, scheduled castes, and other religious minorities with over 50 percent being women. The handicraft industry is primarily an unorganized sector, providing livelihood to over 7 million people, the majority of whom lead a life of hardship and struggle and belong to the economically and socially underprivileged section of the society. But, these artisans, from different locations, across India, despite their hardships, ensure that each of their creations is unique to their place and culture. So, in India, each state has its share of unique products, showcasing their aesthetics to the world and West Bengal is no different.

Though the creations of the Indian artisans are beautiful and are also being accepted across the world it has its share of problems preventing it to grow further. The producers of the handicrafts and the potential customers are not in contact with each other leading to a situation where the producers are unaware of the preferences of their customers [1, 2]. Another major deterrent is the existence of middlemen in this sector which prevents the craftspeople to earn to their potential, even though the customers are paying handsomely for their creations $[2,3,4]$.

The conceptual model proposed in this paper will not only help economically the artisans but will help in the development of the rural areas where the 
majority of the artisans reside thus bringing in social upliftment. After a study of the existing literature on the Indian handicraft sector, the objective of the study is stated. This is followed by research methodology, its findings, the conceptualization of the model, and finally the conclusion.

\section{REVIEW OF EXISTING LITERATURE}

The different aspects of the handicraft sector are discussed in this section.

\subsection{Importance of interaction between customers and craft producers}

Crafts are purchased or processed by consumers as an outlet for their self-expression. According to [5, pp. 23,31], craft consumption involves "skill, knowledge, judgment and passion" which culminates in the creation of something "made and designed by the same person."The craft lovers prefer crafts which are made through traditional process and showcase their creativity in these unique pieces of art [6]. The involvement of the consumers during the production of different pieces of art to satisfy their thirst for selfexpression is quite common [7].

The importance of building a connection between the craft producers and their target customers is evident from the above discussion. Also, the demand for handmade products which is essentially the way Indian handicrafts are prepared has been mentioned thus indicating the potential demand for Indian handicrafts in the world market.

\subsection{The problem of multiple intermediaries in the handicraft sector}

The artisans who are behind these beautiful pieces of art are mostly poverty-stricken and belonging to marginalized communities. They are from the socio-economically backward communities of India and have to fight for existence even though their hands produce crafts that are valued at thousands of millions of rupees per year [8].

This unequal distribution of money received from customers is due to the exploitation of the artisans in the hands of the middlemen. Ironically, these rural artisans are the torch bearers of our rich tradition and heritage who are leading a life of deprivation [20], as they find themselves estranged from the modern amenities and financial independence.

\subsection{State of the Indian handicraft sector}

Indian handicraft industry is primarily in an unorganized sector which as per the survey conducted by the National Sample Survey Organization (NSSO) in the year 2011 - 2012 [9], contributes to about 90 percent of the total employment in India. The survey quantified the total employment (organized and unorganized sector) to about 470 Million of which 390 Million was from the unorganized sector thus indicating the significance of this sector towards the Indian economy.

The increasing opportunity for handicrafts in the world market is proved from the upward trajectory of exports of Indian handicrafts. It has increased to US\$ 3.5 Billion in 2018-19 from US\$ 3.3 Billion in 2016-17 [10]. Despite this growth, Indian handicraft contributes only a mere 2 percent of the world handicraft market [11].

\section{GAP IN EXISTING LITERATURE}

The existing literature on Indian handicrafts has looked into the marketing aspects and also mentioned e-commerce as a channel for promotion and sale of Indian handicrafts in India and the world market $[2,12]$. But research work specifically for the state of West Bengal, a state in the eastern part of India, has been rare and none have tried to look into the specific problems of this region and suggest ways to remove the roadblocks being faced by these craftspersons, thus paving the way for an improved socioeconomic condition for the Bengal's artisans. So, the authors wanted to understand the problems of Bengal's handicraft sector by interacting directly with the artisans, revalidate the points already mentioned in the literature review, identify any issue specific to Bengal, and suggest a framework that will address the issues through the support of technology.

\section{OBJECTIVE}

The objective of this study is to come out with a framework for removing the existing roadblocks being faced by the Indian handicraft sector and making the handicrafts popular and accessible to all target consumers through e-commerce. The study will also look at a suitable model that can lead to the economic and social upliftment of the artisans, who belong to the "bottom of the pyramid".

\section{RESEARCH METHODOLOGY}

Qualitative Content analysis has been used in this paper to identify the problems being faced by the 
artisans by interacting with them through a semistructured interview. Content analysis is considered a good method to analyze text data [13]. The approach taken by a researcher for his or her content analysis depends on the study being conducted and the theoretical inclination of the researcher [14], Researchers while using qualitative content analysis consider mainly the language of communication along with the content or the contextual interpretation of the text [15]. The qualitative content analysis goes much beyond just counting words to understanding the language and to identify a large volume of text into categories that represent related meanings [14]. So, qualitative content analysis can be defined as a process for subjective analysis of contents of text data through a methodical progression of coding and then identifying some patterns or themes from the data [16].

In this present study, data has been collected primarily through semi-structured interviews followed by specific questions to get a deeper insight to develop the initials codes. This approach is similar to what [17] had mentioned, that is, the researchers by using the existing literature start by identifying key variables as initial coding categories. If any text could not be categorized with the initial coding scheme, a new code was given.

\subsection{Data collection steps}

The data was collected through two stages, where the initial stage was used for pre-testing the questionnaire. Based on the pre-test feedbacks, the questionnaire was used to understand the issues being faced by the artisans. The in-depth interview process was so designed that each of the processes through which the artisans go through for producing their crafts is tracked to identify the constraints that the artisans experienced at every stride.

\subsection{Data collection process}

In Kolkata during the winter season, that is from November to February, a lot of handicraft fairs are organized. The authors chose to collect data from these fairs that are visited by artisans from across the state of West Bengal. The biggest and most popular among the fairs is the West Bengal State Handicrafts Fair, popularly known as Hastashilpa Mela, organized by the Government of West Bengal. The duration of the fair was from 23 November 2019 to 23 December 2019 and during this period the authors interviewed different artisans who visited this fair, to collect data. The initial days starting from 23 November 2019 to 27 November 2019 was used for pre-testing the questionnaire where 6 artisans were contacted. Then it was used for conducting in-depth interviews with artisans involved in different crafts. Authors considered interacting with the artisans at the fair instead of visiting different parts of the state to connect with the artisans, as it was cost-effective, time-saving and the authors had the chance to interview artisans who are involved in all major crafts of Bengal.

A semi-structured in-depth interview was used to collect the primary data. In-between specific questions were asked to get a better insight. All the interactions with the artisans were conducted in Bengali, the native language of West Bengal. The narrations were audio recorded for future reference, notes were taken by the authors during the interview process and also notes were taken for any non-verbal cues during this process. Total, 45 artisans were interviewed and the average duration of each interview was 55 minutes.

\subsection{Respondent's profiles}

The artisans interviewed were involved in the most popular crafts of Bengal, who all came to Kolkata, the capital of West Bengal, from different parts of the state to participate in the month-long handicraft fair.

Table 1. Profile of the respondents

\begin{tabular}{|l|c|c|c|l|}
\hline \multirow{2}{*}{ Craft } & \multirow{2}{*}{ Count } & \multicolumn{2}{|c|}{ Count Breakup } & \multirow{2}{*}{ Brief about the crafts } \\
\cline { 3 - 5 } & Male & Female & \\
\hline $\begin{array}{l}\text { Terracota/ } \\
\text { clay dolls }\end{array}$ & 4 & 2 & 2 & $\begin{array}{l}\text { In 'Terracota' craft clay is fire-baked or sun-dried to create } \\
\text { traditional crafts like statues, home décor items, and jewelry. }\end{array}$ \\
\hline Ceramic & 4 & 3 & 1 & $\begin{array}{l}\text { The ceramic products have their usefulness and artistic } \\
\text { representation in different products. }\end{array}$ \\
\hline
\end{tabular}




\begin{tabular}{|c|c|c|c|c|}
\hline $\begin{array}{l}\text { Bell metal } \\
\text { crafts }\end{array}$ & 4 & 4 & 0 & $\begin{array}{l}\text { In the } 18^{\text {th }} \text { century, bell metal or "kaansha" utensils were } \\
\text { considered elite in Bengal's culture. Presently this art form is } \\
\text { passing a difficult phase due to the advent of stainless steel and } \\
\text { other materials. }\end{array}$ \\
\hline $\begin{array}{l}\text { Cane/ } \\
\text { Bamboo } \\
\text { crafts }\end{array}$ & 4 & 2 & 2 & $\begin{array}{l}\text { Beautiful crafts for decoration and utility prepared from } \\
\text { bamboo and cane }\end{array}$ \\
\hline Solapith & 4 & 4 & 0 & $\begin{array}{l}\text { Sola' is Indian cork and is milky white in color. This sponge } \\
\text { wood is used to carve out elaborate and subtle objects ranging } \\
\text { from figurines of gods and goddesses, personalities, and } \\
\text { different models that are called 'solapith'. }\end{array}$ \\
\hline Dhokra & 3 & 3 & 0 & $\begin{array}{l}\text { Dhokra' makes use of the "lost wax casting" method to create } \\
\text { pieces of art. The traditional metal-smiths of Bengal, create } \\
\text { different intricately designed crafts by this method. }\end{array}$ \\
\hline Mats & 3 & 1 & 2 & $\begin{array}{l}\text { Mat or "madur" as it's known in Bengal is a very old cottage } \\
\text { industry }\end{array}$ \\
\hline Patachitra & 3 & 1 & 2 & $\begin{array}{l}\text { "Pat" means cloth and "chitra" is drawing, thus patachitra is } \\
\text { beautiful drawings on scrolls of cloth using natural dyes. }\end{array}$ \\
\hline $\begin{array}{l}\text { Jute } \\
\text { handicrafts }\end{array}$ & 4 & 2 & 2 & $\begin{array}{l}\text { Jute is also known as "golden fiber" and it has many uses } \\
\text { ranging from handbags, textiles, carpets, wall hangings, and } \\
\text { many other decorative items. }\end{array}$ \\
\hline Weavers & 8 & 2 & 6 & $\begin{array}{l}\text { Weavers of handloom sarees, where 'saree' is a garment worn } \\
\text { by Indian women consisting of a length of cotton or silk. }\end{array}$ \\
\hline $\begin{array}{l}\text { Sellers of } \\
\text { sarees }\end{array}$ & 4 & 4 & 0 & $\begin{array}{l}\text { These sellers are selling products weaved by their family } \\
\text { members }\end{array}$ \\
\hline Total & 45 & 28 & 17 & \\
\hline
\end{tabular}

Table 2. Other profile details

\begin{tabular}{|c|c|c|c|c|c|c|c|c|c|}
\hline \multicolumn{3}{|c|}{ Age (Yrs) } & \multicolumn{4}{c|}{ Education Level } & \multicolumn{3}{c|}{ Years in the profession } \\
\hline $\begin{array}{c}20 \text { to } \\
30\end{array}$ & $\begin{array}{c}30 \\
40\end{array}$ & $>40$ & Illiterate & Primary & Secondary & Graduation & $<10$ & $10-20$ & $>20$ \\
\hline $16 \%$ & $62 \%$ & $22 \%$ & $9 \%$ & $44 \%$ & $36 \%$ & $11 \%$ & $16 \%$ & $58 \%$ & $27 \%$ \\
\hline
\end{tabular}

The profile of the 45 artisans is given in Table 1 . Out of the 45 respondents, 62 percent are male. Table 2 provides the other profile details of the respondents.

\subsection{Data analysis process}

To conduct the qualitative data analysis, all the transcripts were arranged into paragraphs and each of these paragraphs was analyzed to determine the meaning units. A meaning unit can be defined as the smallest unit containing information and it is the compilation of the paragraphs related aspects that answer the question set out [18]. Each meaning unit was labeled with a code with respect to the context. So by this method of "open coding process" [19] researchers tried to find out the key concept or concepts related to the issues being faced by the artisans and also referred to the existing literature for validation. After the meaning units have been identified, the original transcripts were referred to multiple times to identify if some parts have been 
missed out. Here the researchers referred to previous literature to identify and include the relevant codes. Next, the coded material was condensed to extract meaning out of the data and divided into broad groups as per different segments of the questionnaire. These categories were identified and finally, the different concepts were analyzed and debated among the researchers as both the authors analyzed the data individually.

\section{FINDINGS}

The qualitative data analysis has identified the following key constraints for the handicraft sector;

a. Exploitation by middlemen The middlemen take advantage of this weakness and exploit the artisans. So, even though the end consumers are paying handsomely for the handicrafts, the makers of these products find themselves in economic hardships.

b. Unaware of market conditions: The lifestyle of consumers is changing and so are their tastes. As this sector is unorganized and is spread across the length and breadth of the state, the artisans tend to continue to create or produce their wares based on their experience, oblivion of the fact that products need to be modified to remain contemporary.

c. The issue with availability and procurement of raw materials: Good quality raw material will lead to better-finished products, but the artisans find difficulty in procuring the right raw materials and at a suitable price. This anomaly results in a compromise in the quality of the crafts or very fewer profit margins for the artisans as the selling price to the middlemen is not proportional to the incremental cost of production.

d. Lack of infrastructure: Lack of infrastructural facilities is one of the major roadblocks for making quality products by the craftsmen and availability of the same to the target customers in India or across the globe.

e. Inadequacy of information: The study has identified the information gap between the Governmental efforts for uplifting the Indian handicraft sector and the target audience who are expected to be benefited from these programs. This lack of awareness could be attributed to the low education level of the majority of the artisans and the applicable rules and regulations.

\section{PROPOSED MODEL}

Based on the parameters that have been identified, a conceptual model (Figure 1) has been developed with the objective to reduce the gap between the producers and the customers across India and specifically for West Bengal. The model also looks at the creation of value for both the handicraft producers and the consumers.

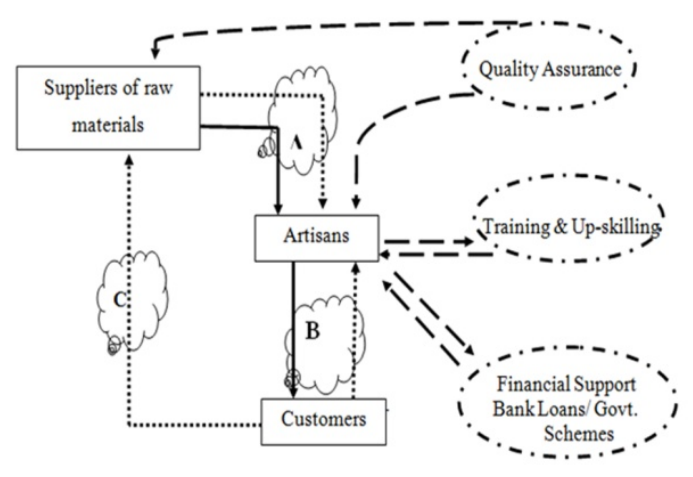

Figure 1 Model with a Holistic Approach

Details of the schematic diagram of the different parties in the proposed model and interaction patterns between them

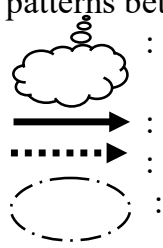

The interactions which are happening online/ over the internet

The direction of interactions

The direction of feedbacks

Support elements for improving the productivity of the artisans and also working towards incremental customer satisfaction.

A: An intelligent system that will connect the right set of suppliers with appropriate artisans depending on the raw materials and processes involved in the production of the specific crafts.

B: A system that will promote relevant products to the customers depending on the usage pattern, buying history, browsing history of the customers. It will be similar to the recommendation tool that is used in established e-commerce sites.

$\mathrm{C}$ : The recommendations and feedback provided by the customers against different arts and crafts available on the online portal will be accessed by both the artisans and suppliers. The suppliers can use this feedback to understand the needs and wishes of the customers and suggest raw materials to the artisans, which is denoted as feedback from the supplier to the artisans.

This model tries to address the major issues that came out of the qualitative content analysis. The center point of this model is the artisans who are in continuous touch with the suppliers of raw materials and the customers who are the other two ends of the 
supply chain. Besides these three entities, the model encompasses the supporting elements namely quality control, training \& up-skill, and financial support.

The backbone of this model is the development of an online marketplace where artisans will be able to connect with potential customers across the world, without depending on the whole sellers and distributors for selling their arts and crafts. The suppliers of different raw materials will also be onboarded to be part of this solution. Depending on the products being produced by the artisans, the system will connect the potential suppliers with the producers. This matching will be driven through an artificial intelligence program. This will take care of the availability of the raw materials for the artisans without the help of middlemen. As the majority of the artisans belong to the economically backward section of the society, working capital is a scarce resource for them. To address this issue the online portal will also have links to local banks for getting loans, details of government schemes, and supports. Handholding the artisans so that they can apply and take advantage of the government supports will be one of the important activities for the organization implementing this model.

\section{CONCLUSION}

The voices of the artisans were collated and analyzed to identify the major problems being faced by the craftspeople. Next through the process of content analysis, the identified elements were classified and ranked which reflected the degree of influence each of these had, in preventing the craft producers to have a better socio-economic status. The conceptual model thus developed by the authors as a result of the qualitative analysis, tries to address the identified limitations and have an end to end process for making available the products which will be accepted by the customers for the right price thus ensuring continuous business for the craftspeople which will result in enhanced economic independence and a sustainable livelihood for the artisans through the use of internet technology.

\section{REFERENCES}

[1] S. Banik, A Study on Financial Analysis of Rural Artisans in India: Issues and Challenges, International Journal of Creative Research Thoughts, Vol 5, No 4, 2017, pp. 2294-2298.

[2] G. Kumari, A.R. Srivastava, Role of e-tailing in boosting the Indian Handicraft
Industry, International Journal of marketing \& Financial Management, Vol 4, No 4, 2016, pp. 27-36.

[3] R. Pathak, M. Sharma, R. Sujatha, RC²@ Craftsvilla. Com Craftsvilla is Revolutionizing through Co-creation: Creating Value for Stakeholders, Journal of Business and Retail Management Research, Vol 12, No 1, 2017, pp. 49-61.

[4] S. Venkataramanaiah, N.G. Kumar, Building competitiveness: a case of handicrafts manufacturing cluster units, Indore Management Journal, Vol 3, No 2, 2011, pp. 27-37.

[5] C. Campbell, The craft consumer: Culture, craft and consumption in a postmodern society, Journal of consumer culture, Vol 5, No 1, 2005, pp. 23-42.

[6] A. Klamer, Crafting Culture: The importance of craftsmanship for the world of the arts and the economy at large, http://www. klamer. nl/docs/crafting. Pdf, 2012.

[7] K.T. Tian, W.O. Bearden, G.L. Hunter, Consumers' need for uniqueness: Scale development and validation, Journal of consumer research, Vol 28, No 1, 2001, pp. 5066.

[8] P.K. Jena, Orissan Handicrafts in the age of globalization: Challenges and opportunities, Orissa Review, Vol 64, No 4, 2007, pp. 19-25.

[9] National Sample Survey Office. Government of India, Employment and unemployment situation in India (NSS Report No. 554(68/10/1), http://mospi.nic.in/sites/default/files/publication _reports/nss_report_554_31jan14.pdf, 2014.

[10] Export Promotion Council for Handicrafts, Handicrafts Exports Data, https://epch.in/index.php?option=com_content $\&$ view $=$ article $\&$ id $=76 \&$ Itemid $=182,2020$

[11] A. Mitra, A. Panja, R. Prasad, Markets for handicrafts, http://businesseconomics.in/markethandicrafts, 2018.

[12] R. Yadav, T. Mahara, An exploratory study to investigate value chain of Saharanpur wooden carving handicraft cluster, International Journal of System Assurance Engineering and Management, Vol 9, No 1, 2018, pp. 147-154. 
[13] S. Cavanagh, Content analysis: concepts, methods and applications, Nurse researcher, Vol 4, No 3, 1997, pp. 5-16.

[14] R.P. Weber, Basic content analysis. No. 49. Sage, 1990.

[15] R. Tesch, Qualitative research-Analysis types and software protocols, Hampshire, UK: The Falmer Press, 1990.

[16] H. Hsieh, S.E. Shannon, Three approaches to qualitative content analysis, Qualitative health research, Vol 15, No 9, 2005, pp. 1277-1288.

[17] W.J. Potter, D. Levine-Donnerstein, Rethinking validity and reliability in content analysis, Journal of Applied Communication Research, Vol 27, No 3, 1999, pp. 258-284.

[18] U.H. Graneheim, B. Lundman, Qualitative content analysis in nursing research: concepts, procedures and measures to achieve trustworthiness, Nurse education today, Vol 24, No 2, 2004, pp. 105-112.

[19] B.L. Berg, H. Lune, An introduction to content analysis, Qualitative research methods for the social sciences, Vol 7, (2001), pp. 238-267.

[20] A.K. Nanda, S. Samanta, Mainstreaming tribals through financial literacy - a review of literature, International Journal of Social

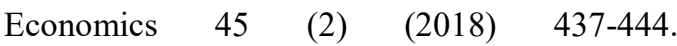
https://doi.org/10.1108/IJSE-12-2016-0371 